\title{
Commentary: Cardiac surgery in the developing world: Matching patient selection to longitudinal care
}

\section{David P. Bichell, MD}

In his 2002 American Association for Thoracic Surgery presidential address, James Cox made the point that outside of North America, Australia, and Europe, 93\% of people have no access to cardiac surgery. Recognizing that episodic traveling surgical teams are common but represent an expensive and nonsustained way to address the maldistribution of care, he outlined 2 tactical goals: leveraging the Internet to make an organized educational and consultative service available to the world to deliver information, and regional hubs where infrastructure is established to deliver surgical care to those regions and to train local surgeons to sustain the practice after the visiting teams have gone. ${ }^{1}$ Jonas $^{2}$ characterized the philanthropic model of bringing patients to an external center as most expensive and least effective. ${ }^{2}$ The visiting single operating team, also characterized as philanthropic, is suboptimal and can "lapse into surgical tourism." 2 The long-term education and support model is the only effective and sustainable model in Jonas' estimation. It entails the building of local infrastructure, visiting fellowships and teams with educational and clinical roles, and the training of local practitioners. ${ }^{2}$

Lacour-Gayet and colleagues ${ }^{3}$ describe a unique hybrid system for the provision of congenital heart operations for complex congenital defects in the developing world that may be a different way to satisfy some of the goals laid out by Cox and Jonas. Underwritten by the Mecenat Chirurgie Cardiaque (MCC) Foundation, patients undergo

\footnotetext{
From the Department of Cardiac Surgery, Monroe Carell, Jr, Children's Hospital, Vanderbilt University Medical Center, Nashville, Tenn.

Disclosures: The author reported no conflicts of interest.

The Journal policy requires editors and reviewers to disclose conflicts of interest and to decline handling or reviewing manuscripts for which they may have a conflict of interest. The editors and reviewers of this article have no conflicts of interest.

Received for publication May 25, 2021; revisions received May 25, 2021; accepted for publication May 25, 2021; available ahead of print June 1, 2021.

Address for reprints: David P. Bichell, MD, Department of Cardiac Surgery, Monroe Carell, Jr, Children's Hospital, Vanderbilt University Medical Center, 5247 Doctors' Office Tower, 2200 Children's Way, Nashville, TN 37232-9292 (E-mail: david.bichell@vumc.org).

J Thorac Cardiovasc Surg 2022;163:424-5

$0022-5223 / \$ 36.00$

Copyright (c) 2021 by The American Association for Thoracic Surgery

https://doi.org/10.1016/j.jtcvs.2021.05.039
}

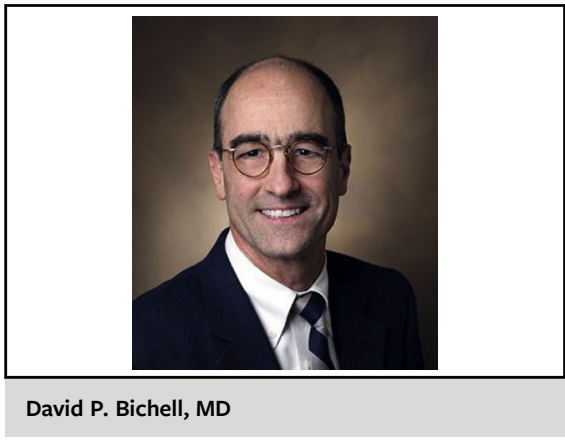

CENTRAL MESSAGE

The success of any model for the provision of surgical care in the developing world depends on a match of patient selection with resources for conscientious follow-up.

surgery in France, but return to home countries where the MCC also funds an impressive system of education for local practitioners who follow the patients longitudinally. The patients accepted for surgical care include single-ventricle patients with MCC-funded subsequent staged operations and lifelong follow-up as demanded by the cardiac condition. The MCC commitment includes "cautiously tracing children surviving with palliative surgery and they will be flown to France if needed." ${ }^{3}$ This system almost satisfies Cox's goals by leveraging the Internet to educate and consult in home countries, and establishing a hub, although not regional, to perform the surgical corrections. The MCC model falls short of developing surgical infrastructure capabilities in the home countries, citing the formidable practical challenges to build such systems worldwide.

Does the MCC model apply resources in the most efficacious way? Can local health care workers be adequately trained to follow single-ventricle patients, whose long-term follow-up is among the most expensive and challenging charges we face today? Transplant-free survival after the Glenn palliation is $90 \%$ at 5 years. ${ }^{4}$ For those surviving to Fontan, transplant-free survival at 20 years is $74 \%{ }^{5}$ and $50 \%$ at 30 years, with frequent hospitalization, ${ }^{6}$ diagnosis and treatment of valve problems, arrhythmia, liver disease, plastic bronchitis, and protein-losing enteropathy. 
The MCC model is an impressive solution, but the inclusion of single-ventricle patients and their local follow-up may be ambitious beyond practicality. The resources committed to 1 single-ventricle patient might take care of several tetralogy of Fallot patients. As always, careful patient selection may be the path to optimal outcomes and optimal resource distribution.

\section{References}

1. Cox JL. Presidential address: changing boundaries. J Thorac Cardiovasc Surg. 2001;122:413-8
2. Jonas RA. Congenital heart surgery in developing countries. Semin Thorac Cardiovasc Surg. 2008;11:3-6.

3. Lacour-Gayet F, Gouton M, Bical O, Lucet V, Roussin R, Leca F. Surgery for severe congenital heart diseases in children from developing nations. J Thorac Cardiovasc Surg. 2022;163:413-23.

4. Scheurer MA, Hill EG, Vasuki N, Maurer S, Graham EM, Bandisode V, et al. Survival after bidirectional cavopulmonary anastomosis: analysis of preoperative risk factors. J Thorac Cardiovasc Surg. 2007;134:82-9.e2.

5. Downing TE, Allen KY, Glatz AC, Rogers LS, Ravishankar C, Rychik J, et al Long-term survival after the Fontan operation: twenty years of experience at a single center. J Thorac Cardiovasc Surg. 2017;154:243-53.e2.

6. Elder RW, McCabe N, Veledar E, Sahu A, Jokhadar M, Kogon B, et al. Transplantfree survival and hospitalizations late after the Fontan palliation. J Am Coll Car diol. 2013;61:E428.
See Article page 413

\section{Commentary: Caring for those often left behind}

Eric R. Griffiths, MD

In this issue of the Journal, Lacour-Gayet and colleagues ${ }^{1}$ report on the amazing work of the Mecenat Chirurgie Cardiaque Foundation in France, whose mission is to "Operate in the best conditions on children from disadvantaged countries suffering from heart malformations." 2 The foundation has treated more than 3000 children since 1996. The purpose of their current article is to report on the 531 patients with "severe" congenital heart disease from among the 3000 who have undergone repair. Although the word "severe" is not commonly used in current classifications of congenital heart disease, the authors chose this designation to convey the increased risk and intensity of care associated with performing palliative and reparative operations in children with advanced disease. The authors note that "severity" reflects "the intensity of resources needed to diagnose and treat a patient with a given diagnosis." 3 This

\footnotetext{
From the Section of Pediatric Cardiothoracic Surgery, Division of Cardiothoracic Surgery, Department of Surgery, University of Utah; and Intermountain Healthcare, Primary Children's Hospital, Salt Lake City, Utah.

Disclosures: The author reported no conflicts of interest.

The Journal policy requires editors and reviewers to disclose conflicts of interest and to decline handling or reviewing manuscripts for which they may have a conflict of interest. The editors and reviewers of this article have no conflicts of interest.

Received for publication May 26, 2021; revisions received May 26, 2021; accepted for publication May 28, 2021; available ahead of print June 24, 2021.

Address for reprints: Eric R. Griffiths, MD, Section of Pediatric Cardiothoracic Surgery, Primary Children's Hospital, 100 N Mario Capecchi Dr, Salt Lake City, UT 84123 (E-mail: Eric.griffiths@hsc.utah.edu).

J Thorac Cardiovasc Surg 2022;163:425-6 $0022-5223 / \$ 36.00$

Copyright (C) 2021 Published by Elsevier Inc. on behalf of The American Association for Thoracic Surgery

https://doi.org/10.1016/j.jtcvs.2021.05.044
}

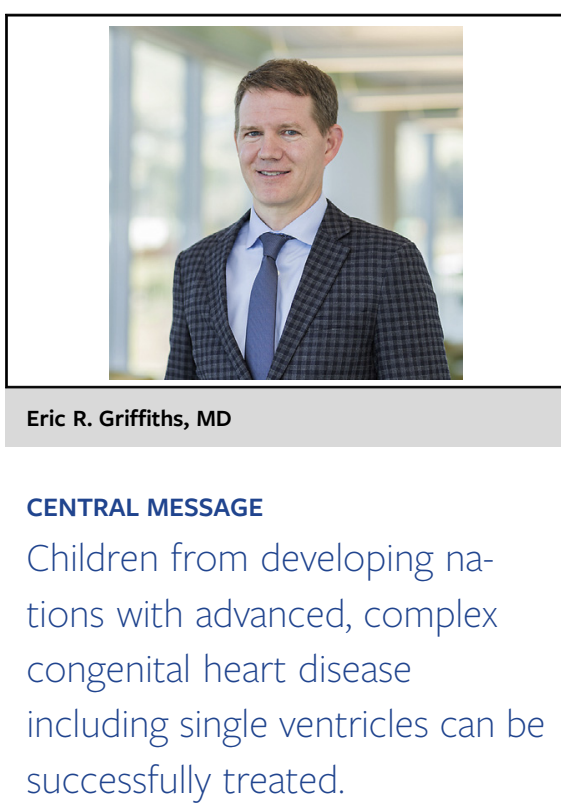

definition captures this high-risk group of patients cared for by the Foundation who would typically be excluded from care rendered on surgical mission trips due to the preference for one-stage, straightforward corrective procedures or possibly undergo staged palliation at local centers not equipped with the facilities, training, or human capital to render similar results that are achieved at established centers in developed nations. ${ }^{4}$ They are caring for those who are often left behind.

Despite the complexity and severity of the patients and disease, the Foundation has achieved remarkable results. Care of the single-ventricle population deserves special recognition. Lacour-Gayet and colleagues report a mean unadjusted perioperative mortality of $6.3 \%$ from a combination of bidirection cavopulmonary connections $(3.9 \%)$, 